\title{
Decision-Making through Uncertain Linguistic Information by Multi-attribute Group: Concerning Credit Guarantee Products Risk
}

\author{
Yong $\mathrm{He}^{1, *}$ and Jian-xing Weng ${ }^{2}$ \\ ${ }^{1}$ School of Finance \& Economy, Hunan University of Technology, 412007 Zhuzhou, China \\ ${ }^{2}$ School of Business, Central South University, 410083 Changsha, China
}

Received: 10 Jul. 2013, Revised: 23 Nov. 2013, Accepted: 24 Nov. 2013

Published online: 1 Jan. 2014

\begin{abstract}
According to the complexity of credit guarantee products risk, a corresponding risk evaluation system is established here. And uncertain linguistic information is adopted to describe the attribute weight and attribute value of evaluation indicators, and thus a multi-attribute group decision-making model of uncertain linguistic information concerning credit guarantee products risks is established. ULWM and ULHA operators are respectively used in this paper to collect evaluation values of synthesized attribute and overall attribute values of groups. And thus the comprehensive evaluation information of alternatives will be obtained. Then, possibility formula is used to construct a possibility matrix based on which we can decide how to arrange the decision-making schemes. At last, through case analysis, the feasibility and efficiency of evaluation of credit guarantee products risks are demonstrated here.
\end{abstract}

Keywords: credit guarantee, risk evaluation, evaluation information by uncertain linguistic information, multi-attribute group decisionmaking system

\section{Introduction}

Credit issue refers to information asymmetry. Poor credit will not only hinder consumption growth but also hamper fund flow [1]. In order to increase such kind of mobility, specialized agencies are needed to provide guaranteed products to the society, that is, credit guaranteed products. The income of credit guarantee products is mainly from the insurance premium, but it faces compensation or reparation payment risks. The asymmetry between risks and incomes brings high risks to credit guarantee products. Therefore, evaluation and control of credit guarantee products is the core part in expanding credit guarantee business. Because of the high risk and non-standard attribute of credit guarantee products, the risk evaluation of products is a rather complicates process. To conduct a reasonable decision-making in terms of credit guarantee products is vital to controlling credit guarantee risk.

In recent years, the academic circle has made great achievements in the theoretical research of credit risk. Some researchers even applied the theory to many areas like risk measurement, control and decision-making of credit guarantee. Taking commercial banks for example, Merton and Bodie [2] conducted a comprehensive research on credit risk and proposed that the portfolio management of financial credit guarantee can diversify products risk. Gendron and Soumare [3], made further analysis of private loans guarantee and based on the VAR model, they analyzed the credit guarantee products risk and offered a theoretical method for risk decision making [4]. made a comparative analysis of credit risk model. Domestic researchers are more specialized in terms of risk evaluation research. Fortes [5] adopted VAR model and FUZZ model respectively to evaluate the risks through a risk evaluation indicator system. Kim and Ahn [6] through basic probability distribution function, adopted D-S method to evaluate the credit risk, and thus to some extent mend the insufficiency like inadequate and uncertain information. It is difficult for people to obtain a large amount of historical data of credit guarantee products, so to adopt the models mentioned above to evaluate risks is not an easy task. As for FUZZ and AHP, they are somehow impacted by functions made by people

\footnotetext{
*Corresponding author e-mail: fei_tiger@126.com
} 
and evaluation indicator weights, therefore, objectivity and reliability can not be assured $[7,8,9,10]$.

\section{Establishment of Risk Evaluation Indicator System of Credit Guarantees Products}

Credit guarantee belongs to a high-risk industry. In order to ensure a reasonable and scientifically evaluation, we have selected some indicators with practical meanings, and strong distinguish ability and representativeness. It should be noted that when building the indicator system we should conduct relevant indicator examination of these indicators so as to decrease the relevance among different indicators and build a risk evaluation system based on risks from three aspects: the basic operation situation, guarantee ability, and anti-guarantee measures of the enterprises guaranteed. Referring the historical documents and according to the complexity of guaranteed products risk, this paper selects the following nine indicators (attributes) to build the evaluation system $u_{j}$.

Table 1: Definition of credit guarantee risk evaluation variable

\begin{tabular}{|c|c|c|}
\hline Variable & Definition & Metric content \\
\hline$u_{1}$ & Moral risk & $\begin{array}{l}\text { The enterprise's credit and the } \\
\text { degree of moral judgments }\end{array}$ \\
\hline$u_{2}$ & Financial risk & $\begin{array}{l}\text { Judgments of the financial } \\
\text { situation }\end{array}$ \\
\hline$u_{3}$ & Market risk & $\begin{array}{l}\text { Judgments on the situation of } \\
\text { the market }\end{array}$ \\
\hline$u_{4}$ & Operation risk & $\begin{array}{l}\text { The operation and } \\
\text { management capacity } \\
\text { evaluation }\end{array}$ \\
\hline$u_{5}$ & $\begin{array}{l}\text { Anti-guarantee } \\
\text { products risk }\end{array}$ & $\begin{array}{l}\text { Judgments of anti-guarantee } \\
\text { products risk }\end{array}$ \\
\hline$u_{6}$ & Policy risk & $\begin{array}{l}\text { The government policies } \\
\text { toward the industry to which } \\
\text { the enterprise belongs }\end{array}$ \\
\hline$u_{7}$ & Associate risk & $\begin{array}{l}\text { internal and external } \\
\text { associated risks of the } \\
\text { inner members }\end{array}$ \\
\hline$u_{8}$ & Historical risk & $\begin{array}{l}\text { whether the enterprise has } \\
\text { experienced poor operation or } \\
\text { not }\end{array}$ \\
\hline$u_{9}$ & $\begin{array}{l}\text { Development } \\
\text { risk }\end{array}$ & $\begin{array}{l}\text { The ability of enterprises } \\
\text { guaranteed to pay debt }\end{array}$ \\
\hline
\end{tabular}

In this paper, we analyze credit guarantee risk evaluation variable by linguistic scale, not a quantitative description.

Moral risk $u_{1}$ : one of the risks faced by credit guarantee products is moral risk of the enterprise guaranteed. The credit and moral standard of enterprises should be reflected through leaders quality, record of borrowing form banks, record of guaranty provided to other partied, credit consciousness of enterprises, tax record, and record of fulfilling economic contracts and so on.

Financial risk $u_{2}$ : it mainly judges the financial status of enterprises, including debt-paying ability, profitability, cash flow situation, and the ratio between loans and funds rises by itself.

Market risk $u_{3}$ : it mainly observes the characteristics of the industry to which the enterprise belongs, lifecycle of enterprises, market competitiveness of enterprises, market share of products of enterprises, and product sales growth situation and so on.

Operation risk $u_{4}$ : it mainly judges the operation and management ability of enterprises, including inventory turnover, accounting receivable turnover, turnover situation of current and fixed assets, and enterprise culture and so on.

Anti-guaranty products risk $u_{5}$ : in the process of credit guarantee, the enterprise needs to provide anti-guarantee collateral and investigate the covering ability and liquidity of anti-guarantee products, and the legitimacy of collateral formalities.

Policy risk $u_{6}$ : it mainly evaluates the government policies toward the industry to which the enterprise belongs, and potential risks caused by the policies involving product itself.

Associate risk $u_{7}$ : it mainly evaluates the internal and external associated risks of the inner members in the enterprise, and potential associated risks cause by business association, capital association with other enterprises.

Historical risk $u_{8}$ : it mainly analyzes and evaluates whether the enterprise has experienced poor operation or not.

Development risk $u_{9}$ : it mainly analyzes the ability of enterprises guaranteed to pay debt on time. Sufficient cash flow as the major payments resources is a vital measure to control guarantee risk. Therefore, it is necessary to evaluate the potential risk of guaranteed items prospect, including intended target, products sales progress, realities of enterprises and expected cash flow.

\section{Decision-making Mode and Theory}

\subsection{Scale and ordering method of uncertain linguistic information}

Assuming the evaluation scale of language information is $S=\left\{s_{a} \mid a=-L, \ldots, L\right\}$, among which $S_{a}$ indicates linguistic variable, and $S_{-L}$ and $S_{L}$ respectively indicate the upper limit and lower limit of linguistic variable actually used by evaluation experts. The number of terms in $S$ is usually odd number.

Example 1. $S=\left\{s_{-5}, \ldots, s_{5}\right\}=\{$ extremely bad, very bad, bad, kind of bad, a little bad, ordinary, a little good, 
kind of good, good, very good, extremely good $\}$ and it satisfies the following conditions: 1, ordering, namely, if $s_{\alpha} \geq s_{\beta}, s_{\alpha} \geq s_{\beta} ; 2$, there is negative operator, namely, $n e g\left(s_{\alpha}\right)=s_{-\alpha} ; 3$, maximization calculation and minimization calculation, namely, if $s_{\alpha} \geq s_{\beta}, \max \left\{s_{\alpha}, s_{\beta}\right\}=s_{\alpha} ; \min \left\{s_{\alpha}, s_{\beta}\right\}=s_{\beta}$. In the integration process, the integration result usually does not match factors in the linguistic evaluation scale $S$. in order to make it easy to count and avoid losing decision information; an extensive linguistic scale $\tilde{S}=\left\{s_{\alpha} \mid \alpha \in[-q, q]\right\}$ is defined on the basis of the old scale, among which $q(q \succ L)$ is a natural number large enough. The extensive linguistic scale still satisfies the conditions 1, 2 and 3, so uncertain linguistic variable can be defined as follows:

Assuming $\tilde{\mu}=\left[s_{a}, s_{b}\right], \tilde{v}=\left[s_{c}, s_{d}\right] \in \tilde{S}$ and assuming $d_{a b}=b-a, d_{c d}=c-d$, the possibility of $\tilde{\mu} \geq \tilde{v}$ is defined as follows:

$$
p(\tilde{\mu} \geq \tilde{v})=\max \left\{1-\max \left[\frac{d-a}{d_{a b}+d_{c d}}, 0\right], 0\right\}
$$

According to this definition, a pair comparison is made in a group of uncertain linguistic information $\left(\tilde{\mu}_{1}, \tilde{\mu}_{2}, \ldots, \tilde{\mu}_{n}\right)$ with the formula (1), and the possibility degree matrix $p=\left(p_{i j}\right)_{n \times m}$ is established, among which $p_{i j}=p\left(\tilde{\mu}_{i} \geq \tilde{\mu}_{j}\right)$. We can prove that possibility matrix is the same with Complementary Judgment Matrix and adopt the order formula raised in the document

$$
v_{i}=\frac{\sum_{j=1}^{n} p_{i j}+\frac{n}{2}-1}{n(n-1)},(i=1,2, \ldots, n)
$$

\subsection{Uncertain linguistic information aggregator}

Assuming $\left(\tilde{a}_{1}, \tilde{a}_{2}, \ldots, \tilde{a}_{n}\right)$ is a set of uncertainty language data, then we define ULWM:

$$
\operatorname{ULWM} \bar{\omega}\left(\tilde{a}_{1}, \tilde{a}_{2}, \ldots, \tilde{a}_{n}\right)=\max \min \left\{\bar{\omega}_{i}, \tilde{a}_{i}\right\}
$$

$\bar{\omega}=\left(\bar{\omega}_{1}, \bar{\omega}_{2}, \ldots, \bar{\omega}_{n}\right)$ is the weighted vector of $\tilde{a}_{i}(i=1,2, \ldots, n)$, and $\tilde{a}_{i}, \bar{\omega}_{i} \in \tilde{S}(i=1,2, \ldots, n)$. The function ULWM called uncertain linguistic weighted maximum and minimum operator, And ULWM operator monotone increasing with the uncertainty linguistic data $\tilde{a}_{i} \in \tilde{S}$. If for any $i=1,2, \ldots, n$ existing $\bar{\omega}_{i} \geq \tilde{a}$, then $\operatorname{ULWM} \bar{\omega}\left(\tilde{a}_{1}, \tilde{a}_{2}, \ldots, \tilde{a}_{n}\right)=\max \left\{\tilde{a}_{i}\right\}$.

$\operatorname{ULHA}_{\omega, w}\left(\tilde{\mu}_{1}, \tilde{\mu}_{2}, \ldots, \tilde{\mu}_{n}\right)=\omega_{1} \tilde{v}_{1} \oplus \omega_{2} \tilde{v}_{2} \oplus \cdots \oplus \omega_{n} \tilde{v}_{n}$ is assumed, that $w=\left(w_{1}, w_{2}, \ldots, w_{n}\right)$ is associated with weight vector ULHA, and $w_{j} \in[0,1](j \in N), \tilde{v}_{j}$ is the elements of in the weighted uncertain linguistic variable group of $\left(\tilde{\mu}_{1}^{\prime}, \tilde{\mu}_{1}^{\prime}, \ldots, \tilde{\mu}_{1}^{\prime}\right)\left(\tilde{\mu}_{1}^{\prime}=n \omega_{i} \tilde{\mu}_{i}, i \in N\right)$. the weight vector of $\left(\tilde{\mu}_{1}, \tilde{\mu}_{2}, \ldots, \tilde{\mu}_{n}\right)(i \in N)$ is $\omega=\left(\omega_{1}, \omega_{2}, \ldots, \omega_{n}\right)$ and $\omega_{j} \in[0,1](j \in N), \sum_{j=1}^{n} \omega_{j}=1$, then we Called ULHA as the uncertainty language function mixed aggregation.

\subsection{The process of decision making}

Step 1. Adopting ULWM operators to collect the information of row $i$ of the uncertain linguistic information matrix $\tilde{R}_{k}=\left(\tilde{r}_{i j}^{(k)}\right)_{i \times j}$, and obtaining the comprehensive attribute evaluation value $\tilde{z}_{i}^{(k)}(\tilde{\omega})$ which obtained by decision maker $d_{k}$ in terms of $x_{i}, \tilde{z}_{i}^{(k)}(\tilde{\omega})=$ $\operatorname{ULWM} \bar{\omega}\left(\tilde{r}_{i 1}^{(k)}, \tilde{r}_{i 2}^{(k)}, \ldots, \tilde{r}_{i n}^{(k)}\right)=\max _{j} \min \left(\bar{\omega}_{j}, \tilde{r}_{i j}^{(k)}\right)$. Among which, $i=1,2, \ldots, n, k=1,2, \ldots, r$.

Step 2. Adopting ULHA operators to collect the comprehensive attribute evaluation value $\tilde{z}_{i}^{(k)}(\tilde{\omega})(i=1,2, \ldots, n, k=1,2, \ldots, l)$ from the decision making solution $x_{i}$ given by decision maker $l$, and thus obtain the group multi-attribute evaluation value: $\tilde{Z}_{i}(\lambda, \omega)=\operatorname{ULHA} \lambda, \omega\left(\tilde{z}_{i}^{(1)}(\bar{\omega}), \tilde{z}_{i}^{(2)}(\bar{\omega}), \ldots, \tilde{z}_{i}^{(l)}(\bar{\omega})\right)=$ $\omega_{1} \tilde{v}_{i}^{(1)} \oplus \omega_{2} \tilde{v}_{i}^{(2)} \oplus \cdots \oplus \omega_{l} \tilde{v}_{i}^{(l)}, i=1,2, \ldots, n$ of decision making $x_{i} . \omega=\left(\omega_{1}, \omega_{2}, \ldots, \omega_{l}\right)$ is the weighted vector associated with ULHA operator, we can adopt blurring quantitative operators to obtain $\omega_{j} \in[0,1](j=1,2, \ldots, l), \sum_{j=1}^{l} \omega_{j}=1$ and $\tilde{v}_{i}^{(k)}$ is the $k$ largest element in a group of weighted uncertain linguistic information: $\left\{l \lambda_{1} \tilde{Z}_{i}^{(1)}(\bar{\omega}), l \lambda_{2} \tilde{Z}_{i}^{(2)}(\bar{\omega}), \ldots, l \lambda_{l} \tilde{Z}_{i}^{(l)}(\bar{\omega})\right\}, l$ is defined as the balance factor.

Step 3. Through use of probability formula (1), making a pair comparison between each value $\tilde{z}_{i}(\lambda, \omega),(i=1,2, \ldots, n)$ of each solution and establishing a probability matrix $p=\left(p_{i j}\right)_{n \times n} \quad$ and $p_{i j}=p\left(\tilde{z}_{i} \geq \tilde{z}_{j}\right),(i, j=1,2, \ldots, n)$. And then formula (2) is adopted to obtain the rank vector $v=\left(v_{1}, v_{2}, \ldots, v_{n}\right)$.

\section{Examples analysis}

Provided that a credit guarantee institute is going to evaluate a risk product, and after preliminary demonstration, the institute draws out three solutions $x_{i}(i=1,2,3) . x_{i}(i=1,2,3)$ and the decision making group composed of five experts $D=\left\{d_{1}, d_{2}, d_{3}, d_{4}, d_{5}\right\}$. The weighted vector is $D=\left\{d_{1}, d_{2}, d_{3}, d_{4}, d_{5}\right\}$ and language scale is $S=\left\{s_{-5}, \ldots, s_{5}\right\}=\{$ extremely low, very low, low, kind of low, a little low, ordinary, a little high, kind of high, high, very high, extremely high\}, and the alternatives will be selected based on the indicators in this paper. Provided that a credit guarantee institute is going to evaluate a risk product, after preliminary demonstration, it three draws three solutions $x_{i}(i=1,2,3), x_{i}(i=1,2,3)$. The a group of decision makers composed of five experts is $D=\left\{d_{1}, d_{2}, d_{3}, d_{4}, d_{5}\right\}$, and the weighted vector is $\lambda=[0.4,0.2,0.2,0.1,0.1]$. The language scale is $S=\left\{s_{-5}, \ldots, s_{5}\right\}=\{$ extremely low, very low, low, kind of low, a little low, ordinary, a little high, kind of high, high, very high, extremely high $\}$ and the candidate solutions are selected according to the indicators in this paper. Assuming that the decision making matrix of 
Table 2: MATRIX $\tilde{R}_{1}$ GIVEN BY EXPERT $d_{1}$

\begin{tabular}{cccc}
\hline & $X_{1}$ & $X_{2}$ & $X_{3}$ \\
\hline$u_{1}$ & {$\left[s_{2}, s_{3}\right]$} & {$\left[s_{1}, s_{3}\right]$} & {$\left[s_{2}, s_{3}\right]$} \\
$u_{2}$ & {$\left[s_{2}, s_{3}\right]$} & {$\left[s_{0}, s_{1}\right]$} & {$\left[s_{1}, s_{2}\right]$} \\
$u_{3}$ & {$\left[s_{3}, s_{4}\right]$} & {$\left[s_{3}, s_{4}\right]$} & {$\left[s_{2}, s_{3}\right]$} \\
$u_{4}$ & {$\left[s_{0}, s_{1}\right]$} & {$\left[s_{1}, s_{3}\right]$} & {$\left[s_{1}, s_{2}\right]$} \\
$u_{5}$ & {$\left[s_{-1}, s_{0}\right]$} & {$\left[s_{0}, s_{1}\right]$} & {$\left[s_{-1}, s_{1}\right]$} \\
$u_{6}$ & {$\left[s_{0}, s_{1}\right]$} & {$\left[s_{-1}, s_{0}\right]$} & {$\left[s_{-1}, s_{0}\right]$} \\
$u_{7}$ & {$\left[s_{-2}, s_{-1}\right]$} & {$\left[s_{-2}, s_{-1}\right]$} & {$\left[s_{-1}, s_{0}\right]$} \\
$u_{8}$ & {$\left[s_{0}, s_{2}\right]$} & {$\left[s_{1}, s_{2}\right]$} & {$\left[s_{1}, s_{2}\right]$} \\
$u_{9}$ & {$\left[s_{1}, s_{2}\right]$} & {$\left[s_{1}, s_{2}\right]$} & {$\left[s_{0}, s_{1}\right]$} \\
\hline
\end{tabular}

Table 3: MATRIX $\tilde{R}_{2}$ GIVEN BY EXPERT $d_{2}$

\begin{tabular}{cccc}
\hline & $X_{1}$ & $X_{2}$ & $X_{3}$ \\
\hline$u_{1}$ & {$\left[s_{-1}, s_{0}\right]$} & {$\left[s_{0}, s_{1}\right]$} & {$\left[s_{-1}, s_{0}\right]$} \\
$u_{2}$ & {$\left[s_{2}, s_{3}\right]$} & {$\left[s_{1}, s_{2}\right]$} & {$\left[s_{2}, s_{3}\right]$} \\
$u_{3}$ & {$\left[s_{1}, s_{2}\right]$} & {$\left[s_{0}, s_{1}\right]$} & {$\left[s_{2}, s_{3}\right]$} \\
$u_{4}$ & {$\left[s_{-1}, s_{0}\right]$} & {$\left[s_{-2}, s_{-1}\right]$} & {$\left[s_{-1}, s_{0}\right]$} \\
$u_{5}$ & {$\left[s_{-2}, s_{-1}\right]$} & {$\left[s_{-1}, s_{0}\right]$} & {$\left[s_{-2}, s_{-1}\right]$} \\
$u_{6}$ & {$\left[s_{-1}, s_{0}\right]$} & {$\left[s_{-2}, s_{0}\right]$} & {$\left[s_{-1}, s_{0}\right]$} \\
$u_{7}$ & {$\left[s_{-3}, s_{-2}\right]$} & {$\left[s_{-2}, s_{-1}\right]$} & {$\left[s_{-2}, s_{-1}\right]$} \\
$u_{8}$ & {$\left[s_{0}, s_{2}\right]$} & {$\left[s_{0}, s_{1}\right]$} & {$\left[s_{0}, s_{1}\right]$} \\
$u_{9}$ & {$\left[s_{1}, s_{2}\right]$} & {$\left[s_{1}, s_{2}\right]$} & {$\left[s_{0}, s_{1}\right]$} \\
\hline
\end{tabular}

Table 4: MATRIX $\tilde{R}_{3}$ GIVEN BY EXPERT $d_{3}$

\begin{tabular}{cccc}
\hline & $X_{1}$ & $X_{2}$ & $X_{3}$ \\
\hline$u_{1}$ & {$\left[s_{1}, s_{2}\right]$} & {$\left[s_{2}, s_{3}\right]$} & {$\left[s_{1}, s_{3}\right]$} \\
$u_{2}$ & {$\left[s_{1}, s_{2}\right]$} & {$\left[s_{2}, s_{3}\right]$} & {$\left[s_{2}, s_{3}\right]$} \\
$u_{3}$ & {$\left[s_{1}, s_{2}\right]$} & {$\left[s_{2}, s_{3}\right]$} & {$\left[s_{1}, s_{2}\right]$} \\
$u_{4}$ & {$\left[s_{-2}, s_{-1}\right]$} & {$\left[s_{-2}, s_{0}\right]$} & {$\left[s_{-1}, s_{0}\right]$} \\
$u_{5}$ & {$\left[s_{-1}, s_{0}\right]$} & {$\left[s_{-1}, s_{0}\right]$} & {$\left[s_{-2}, s_{-1}\right]$} \\
$u_{6}$ & {$\left[s_{1}, s_{2}\right]$} & {$\left[s_{2}, s_{3}\right]$} & {$\left[s_{0}, s_{1}\right]$} \\
$u_{7}$ & {$\left[s_{-1}, s_{0}\right]$} & {$\left[s_{-2}, s_{-1}\right]$} & {$\left[s_{-2}, s_{-1}\right]$} \\
$u_{8}$ & {$\left[s_{0}, s_{1}\right]$} & {$\left[s_{-1}, s_{0}\right]$} & {$\left[s_{-2}, s_{-1}\right]$} \\
$u_{9}$ & {$\left[s_{0}, s_{1}\right]$} & {$\left[s_{-1}, s_{0}\right]$} & {$\left[s_{-1}, s_{0}\right]$} \\
\hline
\end{tabular}

uncertain linguistic information variables given by the five experts is $\tilde{R}_{k}=\left(\tilde{r}_{i j}^{(k)}\right)_{3 \times 9}(k=1,2,3,4,5)$ :

Step 1. Adopting ULWM operators to collect information in every row of the matrix given by each expert, and assign weighted vectors to nine attributes:

$$
\begin{gathered}
\bar{\omega}=\left(\left[s_{1}, s_{3}\right],\left[s_{3}, s_{4}\right],\left[s_{-2}, s_{0}\right],\left[s_{0}, s_{2}\right],\left[s_{-2}, s_{-1}\right],\right. \\
\left.\left[s_{1}, s_{2}\right],\left[s_{-3}, s_{-2}\right],\left[s_{2}, s_{4}\right],\left[s_{0}, s_{1}\right]\right)
\end{gathered}
$$

\section{Table 5: MATRIX $\tilde{R}_{4}$ GIVEN BY EXPERT $d_{4}$}

\begin{tabular}{cccc}
\hline & $X_{1}$ & $X_{2}$ & $X_{3}$ \\
\hline$u_{1}$ & {$\left[s_{1}, s_{3}\right]$} & {$\left[s_{1}, s_{3}\right]$} & {$\left[s_{-1}, s_{0}\right]$} \\
$u_{2}$ & {$\left[s_{3}, s_{4}\right]$} & {$\left[s_{2}, s_{4}\right]$} & {$\left[s_{3}, s_{4}\right]$} \\
$u_{3}$ & {$\left[s_{2}, s_{3}\right]$} & {$\left[s_{3}, s_{4}\right]$} & {$\left[s_{2}, s_{3}\right]$} \\
$u_{4}$ & {$\left[s_{0}, s_{1}\right]$} & {$\left[s_{1}, s_{2}\right]$} & {$\left[s_{1}, s_{2}\right]$} \\
$u_{5}$ & {$\left[s_{-1}, s_{0}\right]$} & {$\left[s_{0}, s_{1}\right]$} & {$\left[s_{-1}, s_{2}\right]$} \\
$u_{6}$ & {$\left[s_{0}, s_{1}\right]$} & {$\left[s_{-1}, s_{0}\right]$} & {$\left[s_{-1}, s_{0}\right]$} \\
$u_{7}$ & {$\left[s_{-2}, s_{-1}\right]$} & {$\left[s_{-2}, s_{-1}\right]$} & {$\left[s_{-1}, s_{0}\right]$} \\
$u_{8}$ & {$\left[s_{0}, s_{2}\right]$} & {$\left[s_{1}, s_{2}\right]$} & {$\left[s_{1}, s_{2}\right]$} \\
$u_{9}$ & {$\left[s_{1}, s_{2}\right]$} & {$\left[s_{0}, s_{1}\right]$} & {$\left[s_{0}, s_{1}\right]$} \\
\hline
\end{tabular}

\section{Table 6: MATRIX $\tilde{R}_{5}$ GIVEN BY EXPERT $d_{5}$}

\begin{tabular}{cccc}
\hline & $X_{1}$ & $X_{2}$ & $X_{3}$ \\
\hline$u_{1}$ & {$\left[s_{2}, s_{3}\right]$} & {$\left[s_{1}, s_{2}\right]$} & {$\left[s_{2}, s_{3}\right]$} \\
$u_{2}$ & {$\left[s_{1}, s_{2}\right]$} & {$\left[s_{1}, s_{2}\right]$} & {$\left[s_{3}, s_{4}\right]$} \\
$u_{3}$ & {$\left[s_{3}, s_{4}\right]$} & {$\left[s_{3}, s_{4}\right]$} & {$\left[s_{2}, s_{3}\right]$} \\
$u_{4}$ & {$\left[s_{0}, s_{1}\right]$} & {$\left[s_{2}, s_{4}\right]$} & {$\left[s_{1}, s_{2}\right]$} \\
$u_{5}$ & {$\left[s_{-1}, s_{0}\right]$} & {$\left[s_{0}, s_{1}\right]$} & {$\left[s_{-1}, s_{2}\right]$} \\
$u_{6}$ & {$\left[s_{0}, s_{1}\right]$} & {$\left[s_{-1}, s_{0}\right]$} & {$\left[s_{-1}, s_{0}\right]$} \\
$u_{7}$ & {$\left[s_{-2}, s_{-1}\right]$} & {$\left[s_{-3}, s_{-1}\right]$} & {$\left[s_{-1}, s_{0}\right]$} \\
$u_{8}$ & {$\left[s_{0}, s_{2}\right]$} & {$\left[s_{1}, s_{2}\right]$} & {$\left[s_{1}, s_{2}\right]$} \\
$u_{9}$ & {$\left[s_{1}, s_{2}\right]$} & {$\left[s_{1}, s_{2}\right]$} & {$\left[s_{0}, s_{1}\right]$} \\
\hline
\end{tabular}

So we can obtain the comprehensive evaluation values of each candidate solution given by each expert:

$$
\begin{aligned}
& \tilde{Z}_{1}^{(1)}(\tilde{\omega})=\left[s_{2}, s_{3}\right], \tilde{Z}_{2}^{(1)}(\tilde{\omega})=\left[s_{1}, s_{2}\right], \tilde{Z}_{3}^{(1)}(\tilde{\omega})=\left[s_{2}, s_{3}\right] \\
& \tilde{Z}_{1}^{(2)}(\tilde{\omega})=\left[s_{2}, s_{3}\right], \tilde{Z}_{2}^{(2)}(\tilde{\omega})=\left[s_{1}, s_{2}\right], \tilde{Z}_{3}^{(2)}(\tilde{\omega})=\left[s_{2}, s_{3}\right] \\
& \tilde{Z}_{1}^{(3)}(\tilde{\omega})=\left[s_{1}, s_{2}\right], \tilde{Z}_{2}^{(3)}(\tilde{\omega})=\left[s_{2}, s_{3}\right], \tilde{Z}_{3}^{(3)}(\tilde{\omega})=\left[s_{1}, s_{3}\right] \\
& \tilde{Z}_{1}^{(4)}(\tilde{\omega})=\left[s_{1}, s_{3}\right], \tilde{Z}_{2}^{(4)}(\tilde{\omega})=\left[s_{1}, s_{3}\right], \tilde{Z}_{3}^{(4)}(\tilde{\omega})=\left[s_{3}, s_{4}\right] \\
& \tilde{Z}_{1}^{(5)}(\tilde{\omega})=\left[s_{2}, s_{3}\right], \tilde{Z}_{2}^{(5)}(\tilde{\omega})=\left[s_{1}, s_{3}\right], \tilde{Z}_{3}^{(5)}(\tilde{\omega})=\left[s_{3}, s_{4}\right]
\end{aligned}
$$

Step 2. Adopting ULHA operators to collect the comprehensive attribute values $\tilde{Z}_{i}^{(k)}(\tilde{\omega})$ of candidate solutions $x_{i}$ given by five experts. Assuming that the weighted vector of ULHA operators is $\omega=(0.5,0.2,0.1,0.1,0.1)$, then we can obtain the comprehensive attribute values: $\tilde{Z}_{1}(\lambda, \omega)=\left[s_{2.55}, s_{4.00}\right], \quad \tilde{Z}_{2}(\lambda, \omega)=$ $\left[s_{1.40}, s_{3.00}\right], \tilde{Z}_{3}(\lambda, \omega)=\left[s_{2.80}, s_{4.30}\right]$.

Step 3. Adopting the probability formula (1) of uncertain linguistic information to establish the 
probability matrix $P=\left(p_{i j}\right)_{3 \times 5}$ :

$$
P=\left[\begin{array}{lll}
0.50 & 0.85 & 0.41 \\
0.15 & 0.50 & 0.06 \\
0.59 & 0.94 & 0.50
\end{array}\right]
$$

And then, based on formula (2) we can obtain the rank vector of matrix $P$, and arrange the solutions according to the components: $v=(0.3767,0.2017,0.4217)$. After that we get $x_{2} \prec x_{1} \prec x_{3}$. Because the decision making attribute of credit guarantee products risk is of cost type, the minimum value is the best, so the second solution is the best, which means that we should choose the second solution.

\section{Conclusions}

In the real situation of credit guarantee products risk decision making, because every product possess its own unique characteristics, it is very difficult to use precise data to indicate the risk factors needing analysis, therefore, the decision maker has to describe the product risk conditions with language. This paper, through the risk evaluation indicator system of credit guarantee products and uncertain linguistic information group multi-attribute decision making model, overcomes the difficulty of using specific numbers to describe risks. In this model, ULWM operator is used to weight and collect the decision making information of uncertain linguistic information variables according to its importance. And ULHA operator is used to collect and weight the comprehensive evaluation information data given by each expert. Through fuzzy complementary matrix, we can get the rank vectors and then arrange them according to the size. By doing this, impacts posed by subjective factors of experts in the process of decision making can be reduced. Example analysis shows that through uncertain linguistic information variables and reasonable use of ULWM and ULHA operators, the multi-attribute group decision making model of uncertain linguistic information is a more precise and improved method. It is should be noticed that this paper only discusses decision making information, weighted value of solution attribute, and attribute value given by each expert, and all these aspects are within the area of linguistic evaluation information. In fact, there are other situations existing, therefore, and in this case, further study is necessary.

\section{Acknowledgement}

This work was supported by National Social Science Foundation of China(Grant No. 13BGL039) and Social Science Youth Foundation of Ministry of Education of China (Grant No. 11YJCZH054) .

\section{References}

[1] F. Herrera and E. Herrera-Viedma, Linguistic Decision Analysis: Steps for Solving Decision Problems under Linguistic Information J. Fuzzy Set. Syst., 115, 67-82 (2000).

[2] R. C Merton and Z. Bodie, On the Management of Financial Guarantees, J. Finan. Mange., 21, 87-109 (1992).

[3] M. Gendron, V. S Lai, I. Soumare, Analyses of Private Loan Guarantee Portfolios, J. Res. Int. Bus. Finan., 16, 395-415 (2002).

[4] S. E. M Darwish and M. Y Hussein, Contribution of Coherent Neutral-Pion Photoproduction Channel to the GerasimovDrell-Hearn Sum Rule for the Deuteron, Appl. Math. Inf. Sci., 3, 321-334 (2009).

[5] I. Fortes, L. Moralópez, R. Morales, F. Triguero, Inductive learning models with missing values, J. Math. Comput. Model, 44, 790-806 (2006).

[6] S. H Kim and B. S Ahn, Group decision making procedure considering preference strength under incomplete information, J. Comput. Oper. Res., 24, 101-1112 (1997).

[7] I. Saleem, H. Nawaz, I. Ahmed, S. M. Abbas, Analytical Evaluation of Tri-band Printed Antenna, Information Sciences Letters, 1, 85-89 (2012).

[8] D. Ben-Arieh and Z. Chen, Linguistic Group Decisionmaking: Opinion Aggregation and Measures of Consensus, J. Fuzzy Optim. Decis. Mak., 5, 71-386 (2006).

[9] Z. Y He and Y. Q Han, Integration of Evidence-based Risk Assessment Method for Credit Guarantee, Statistics and Decision, 2, 40-43 (2006). (in Chinese)

[10] Y. M Wang, J. B Yang, D. L Xu, A Preference Aggregation Method through the Estimation of Utility Intervals, J. Compu. Opera. Res., 32, 2007-2032(2006) . 


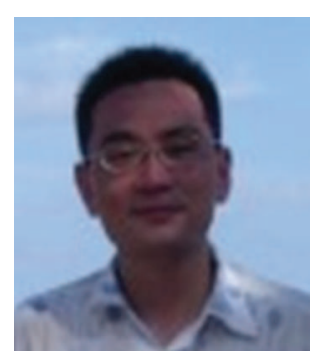

Yong He was born
in China in 1974. He
received the B.E. degree
in finance from Peking
University, Beijing, China,
the M.M. degree in Business
Administration r from
Tongji University, Shanghai,
China, and the Ph.D. degree
in accounting from School of

Business of Central South University, Changsha, China. Since December 2005, he has been an associate professor of School of Finance, Hunan University of Technology. His research interests include Investment and financing management, intelligent control and information management.

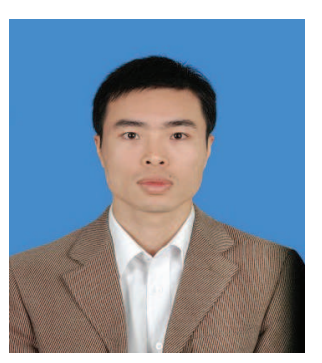

\section{Jian-xing Weng} was born in China in 1977. He received the B.S. degree in electrical engineering from the Technology, Changsha, China, the M.M. degree in tech-nical economics from Changsha University of Science and Technology, Changsha, China, and the Ph.D. degree in business administration from School of Business of Central South University, Changsha, China. His research interests include finance management and information management. 